\title{
Biomimetic Scaffolds Obtained by Electrospinning of Collagen-Based Materials: Strategies to Hinder the Protein Denaturation
}

\author{
Giorgia Montalbano ${ }^{1,+}+\mathbb{D}$, Clarissa Tomasina ${ }^{2,+}$, Sonia Fiorilli ${ }^{1}$, Sandra Camarero-Espinosa ${ }^{2,3,4}$, \\ Chiara Vitale-Brovarone ${ }^{1, *}$ and Lorenzo Moroni ${ }^{2}$ (D)
}

1 Department of Applied Science and Technology, Politecnico di Torino, 10129 Torino, Italy; giorgia.montalbano@polito.it (G.M.); sonia.fiorilli@polito.it (S.F.)

2 Complex Tissue Regeneration Department, MERLN Institute for Technology-Inspired Regenerative Medicine, Maastricht University, Universiteitssingel 40, 6229 ET Maastricht, The Netherlands; c.tomasina@maastrichtuniversity.nl (C.T.); sandra.camarero@polymat.eu (S.C.-E.); 1.moroni@maastrichtuniversity.nl (L.M.)

3 POLYMAT, University of the Basque Country UPV/EHU, 20018 San Sebastián, Spain

4 IKERBASQUE, Basque Foundation for Science, 48009 Bilbao, Spain

* Correspondence: chiara.vitale@polito.it

+ Equal contribution.

check for updates

Citation: Montalbano, G.; Tomasina, C.; Fiorilli, S.; Camarero-Espinosa, S.; Vitale-Brovarone, C.; Moroni, L. Biomimetic Scaffolds Obtained by Electrospinning of Collagen-Based Materials: Strategies to Hinder the Protein Denaturation. Materials 2021, 14, 4360. https://doi.org/10.3390/ ma14164360

Academic Editor: Valery Kulichikhin

Received: 2 July 2021

Accepted: 2 August 2021

Published: 4 August 2021

Publisher's Note: MDPI stays neutral with regard to jurisdictional claims in published maps and institutional affiliations.

Copyright: (C) 2021 by the authors Licensee MDPI, Basel, Switzerland. This article is an open access article distributed under the terms and conditions of the Creative Commons Attribution (CC BY) license (https:/ / creativecommons.org/licenses/by/ $4.0 /)$.

\begin{abstract}
The use of biomaterials and scaffolds to boost bone regeneration is increasingly gaining interest as a complementary method to the standard surgical and pharmacological treatments in case of severe injuries and pathological conditions. In this frame, the selection of biomaterials and the accurate assessment of the manufacturing procedures are considered key factors in the design of constructs able to resemble the features of the native tissue and effectively induce specific cell responses. Accordingly, composite scaffolds based on type-I-collagen can mimic the composition of bone extracellular matrix (ECM), while electrospinning technologies can be exploited to produce nanofibrous matrices to resemble its architectural organization. However, the combination of collagen and electrospinning reported several complications due to the frequent denaturation of the protein and the variability of results according to collagen origin, concentration, and solvent. In this context, the strategies optimized in this study enabled the preparation of collagen-based electrospun scaffolds characterized by about $100 \mathrm{~nm}$ fibers, preserving the physico-chemical properties of the protein thanks to the use of an acetic acid-based solvent. Moreover, nanoparticles of mesoporous bioactive glasses were combined with the optimized collagen formulation, proving the successful design of composite scaffolds resembling the morphological features of bone ECM at the nanoscale.
\end{abstract}

Keywords: biomimetic scaffolds; electrospinning; type I collagen; hybrid formulations; bone tissue engineering

\section{Introduction}

Biomaterial-based approaches to improve the regeneration of compromised and damaged tissues are increasingly emerging as promising alternatives to overcome the limits presented by the standard surgical and pharmacological treatments [1-3]. Especially in the field of bone regeneration applications, the development of scaffolds and biomaterials able to promote and guide the formation of new healthy tissue is considered crucial due to the ever-increasing occurrence of bone loss and damage caused by traumatic or pathological conditions [4-6].

In this context, biomimetic and bioactive materials have proved to increase their effectiveness when exploited to design constructs mimicking the structural features of the native extracellular matrix (ECM) [7-9]. In the specific case of bone tissue, the natural ECM is a complex hierarchically organized structure mainly consisting of type I collagen fibrils 
and nanosized hydroxyapatite crystals. Therefore, nano-structured composite scaffolds based on type I collagen can represent biomimetic substrates able to boost the regeneration of bone tissue, reproducing its native chemical and nano-architectural features $[9,10]$.

Besides additive manufacturing technologies, electrospinning represents a promising tool to produce structurally biomimetic scaffolds since it enables the creation of nanofibrous constructs presenting fiber diameters ranging from a few microns to less than $100 \mathrm{~nm}$, thus mimicking the features of the bone ECM at the micro- and nanoscale [11,12]. The overall process consists of the deposition of dry fibers, starting from polymeric solutions that are extruded upon application of an electric field, wherein the deposition and the morphological features of the resulting mats can be partially controlled by the optimization of the process parameters as well as the physico-chemical properties of the material $[11,13,14]$. Thanks to this manufacturing process, nanostructured scaffolds characterized by a high surface area-to-volume ratio can be realized and possibly exploited as biomimetic matrices as well as efficient delivery platforms upon simple modifications and functionalization of the constructs, as reported in different studies $[1,13,15]$.

In the field of bone tissue engineering, type I collagen, being the main organic component of the bone ECM, represents the most suitable substrate thanks to its well-known high biocompatibility and ability to promote cell adhesion and proliferation $[10,16]$. The combination of collagen with electrospinning technologies has already proved to be promising in different fields of tissue engineering. In this frame, the study of Rho and coworkers demonstrated that collagen electrospun matrices coated with ECM proteins were very effective as wound-healing accelerators in early-stage wound healing [17]. Moreover, considering the key role of collagen in the composition of native blood vessels, tubular electrospun scaffolds have been explored to actively support vascular regeneration [13].

Despite the chance of creating nanostructured scaffolds reproducing the dimensions of collagen fibrils present in vivo (ranging from 20 to $40 \mathrm{~mm}$ ), in the use of collagen for electrospinning applications several authors reported critical aspects concerning the potential denaturation of the protein, mainly due to the used organic solvents (e.g., 1,1,3,3,3hexafluoro-2-propanol (HFP) and 2,2,2-trifluoroethanol (TFE)) and to the process parameters $[11,18,19]$. On the other hand, the use of non-toxic solvents such as ethanol or PBS solutions often led to the formation of mats with larger and less homogeneous fibers, with high concentrations of deposited salts [20].

Based on these limitations, synthetic polymers are normally preferred thanks to their easier processability, in addition to the enhanced stability and mechanical properties of the resulting scaffolds $[15,21]$. However, the potential residues of toxic solvents and the synthetic nature of the substrates greatly affect the final biocompatibility and bioactivity of the constructs $[15,19]$.

In the case of naturally derived polymers such as type I collagen, just a few works in the literature documented the use of non-toxic benign solvents, often without reporting evidence on the effective preservation of the physico-chemical properties of the protein $[12,18,19]$. Moreover, several studies showed morphological features of the scaffolds significantly different on the base of the collagen origin, concentration and solvents used $[11,14,18,20]$.

Despite the combination of type I collagen with other synthetic and natural polymers for electrospinning applications have been already documented, few studies reported the inclusion of inorganic phases for the development of electrospun composite collagen scaffolds [12,13,19,22]. Considering the natural composition of bone, Zhou and coworkers [19] reported the successful electrospinning of collagen and nanohydroxyapatite suspensions, obtaining homogeneous scaffolds characterized by fibers in the range of 600 to $900 \mathrm{~nm}$, with a good dispersion of the inorganic phase even at high concentrations.

Besides hydroxyapatite (HA), the use of mesoporous bioactive glasses (MBGs) for bone tissue engineering has been widely reported thanks to their high bioactive character and their ability to promote the deposition of HA crystals in presence of physiological fluids [23-26]. Moreover, their high specific surface area can be exploited for the incorporation 
and/or grafting of a wide range of therapeutic agents and biomolecules, acting as efficient delivery nanocarriers [27-30]. Despite the combination of collagen and MBGs have been largely explored to produce bone scaffolds with different manufacturing techniques, data regarding the processability of these systems with electrospinning technologies are still lacking [26,31-34].

In this setting, the present work aimed at exploring the design of biomimetic nanostructured scaffolds based on bovine type I collagen derived from Achilles tendon, further investigating the processability of MBG containing hybrid formulations to obtain composite systems. To this aim, a solution of acetic acid/ethyl acetate/water $\left(\mathrm{AA} / \mathrm{EA} / \mathrm{H}_{2} \mathrm{O}\right)$ and a solution of $40 \%$ acetic acid in water (AA) were explored as non-toxic solvents dissolving increasing collagen concentrations and evaluating the influence over the final physicochemical properties of collagen as well as material processability. The selection of collagen concentrations and solvents were based on previous studies reported in the literature and aimed at preserving the structural properties of collagen, avoiding its denaturation [12,35]. In parallel, the electrospinning conditions have been optimized exploiting a plate collector, to obtain homogeneous and defect-less scaffolds, morphologically assessed by means of scanning electron microscopy (SEM). Upon optimization of the collagen solution, MBG particles were incorporated to confirm the processability of hybrid formulations with electrospinning technologies in order to obtain more biomimetic composite scaffolds.

\section{Materials and Methods}

\subsection{Preparation of Collagen-Based Materials for Electrospinning}

To develop and optimize collagen-based formulations suitable for electrospinning applications, bovine type I collagen powders derived from Achilles tendon (BOV-COL) (Kensey Nash Corporation, Greater Philadelphia Area, Great Lakes, Northeastern US) were dissolved at different concentrations ranging between 12 and $25 \mathrm{wt} \%$ in two different solvents: a solution of acetic acid/ethyl acetate/water $\left(\mathrm{AA} / \mathrm{EA} / \mathrm{H}_{2} \mathrm{O}\right)$ with a ratio of 40:30:30 and a solution of $40 \%$ acetic acid in water (AA). To promote the proper dissolution of collagen powders considering the high concentrations, the solutions were stirred at $4{ }^{\circ} \mathrm{C}$ overnight and used immediately after preparation.

After the optimization of collagen concentration and solvent, nanoparticles of mesoporous bioactive glasses (MBG_SG), prepared following a sol-gel route previously optimized by the authors (Supplementary Material) [36,37], were used to obtain bioactive hybrid formulations. After complete dissolution of collagen powders in $40 \%$ AA at $4{ }^{\circ} \mathrm{C}$, MBG_SG nanoparticles were sonicated in the same solvent using a horn sonicator (Sonoplus Ultraschall-Homogenisation HD 2200, $20 \mathrm{kHz} \pm 500 \mathrm{~Hz}$ frequency, 50\% amplitude) for $6 \mathrm{~min}$ and subsequently incorporated into the collagen solution to obtain final concentrations of $5 \mathrm{wt} \%$. The resulting suspension was stirred for $1 \mathrm{~h}$ at room temperature to obtain a homogeneous system and immediately used for electrospinning tests.

\subsection{Circular Dichroism (CD)}

CD analyses were performed with a JASCO J-815 circular dichroism spectropolarimeter, (Jasco, Mary's Court, Easton, MD, USA) equipped with a Xe arc lamp, to record data in the far-UV spectral range. CD spectra resulted from the average of 3 scans recorded for each sample at $50 \mathrm{~nm} / \mathrm{sec}$ scanning rate. The measurements were carried out using a quartz circular cuvette with a path length of $0.1 \mathrm{~mm}$ in the $180-260 \mathrm{~nm}$ wavelength range. Collagen samples recovered after dissolution in the different solvents $\left(\mathrm{AA} / \mathrm{EA} / \mathrm{H}_{2} \mathrm{O}, 40 \%\right.$ AA) and after electrospinning were prepared using a concentration of $0.1 \mathrm{mg} / \mathrm{mL}$ in distilled water. All spectra were corrected after acquisition using the correspondent solvent medium as baseline (distilled water) and analyzed at room temperature $\left(20^{\circ} \mathrm{C}\right)$.

\subsection{Rheology}

All the rheological tests were performed using a DHR-2 controlled stress rotational Rheometer (TA Instruments, Waters, New Castle, IN, USA) equipped with a parallel plate 
geometry with a diameter of $20 \mathrm{~mm}$ and a Peltier plate system to constantly control the system temperature. Flow ramp tests at $23{ }^{\circ} \mathrm{C}$ were conducted to investigate the viscosity of the different collagen solutions and the final suspension over a wide range of shear rates $\left(0.01-1000 \mathrm{~s}^{-1}\right)$.

\subsection{Electrospinning Tests}

The electrospinning tests were performed using a custom-made electrospinning setup equipped with a temperature and humidity control system. A plate collector and a spinneret tip of $21 \mathrm{G}(0.8 \mathrm{~mm}$ internal diameter $)$ were used for all the tests in order to obtain randomly oriented fibrous mats.

After preparation, the different collagen-based formulations were left $30 \mathrm{~min}$ at room temperature before loading into $5 \mathrm{~mL}$ syringes.

Electrospinning tests were conducted at a distance between spinneret tip and collector of $10-15 \mathrm{~cm}$ (working distance) with voltage and flow rate ranging from 18.5 to $20 \mathrm{kV}$ and 0.05 to $0.15 \mathrm{~mL} / \mathrm{h}$, respectively, and keeping a constant temperature of $23{ }^{\circ} \mathrm{C}$ at $40 \%$ humidity. The resulting electrospun matrices were removed from the collector and left to dry overnight at room temperature before analysis.

\subsection{Scaffold Characterisation}

\subsubsection{Scanning Electron Microscopy (SEM) and Dispersive X-ray Analysis (EDX)}

For investigation of fiber diameter, mesh morphology and particle distribution, samples of electrospun scaffolds were punched into $12 \mathrm{~mm}$ disks and gold coated using a Cressington Sputter Coated 180 auto and then imaged using a Jeol JSM-IT200 InTouchScope scanning electron microscope (JEOL, Peabody, MA, USA) at V $=10 \mathrm{keV}$.

For the analysis of scaffold composition, scaffolds were studied under the energy dispersive X-ray analyzer (EDX) coupled to the Jeol JSM-IT200 microscope.

\subsubsection{Fourier Transform Infrared Spectroscopy (FTIR)}

FTIR spectroscopy (Perkin Elmer Spectrum 1000) (JEOL, Peabody, MA, USA) was performed in the $4000-500 \mathrm{~cm}^{-1}$ range at a spectral resolution of $0.09 \mathrm{~cm}^{-1}$ and accumulation of 32 scans on the optimized electrospun collagen scaffolds with and without MBG_SG particles, compared with non-treated bovine collagen powders.

For the tests, the electrospun scaffolds were dried overnight, peeled from the aluminum foil, and used for measurement.

\section{Results and Discussion}

\subsection{Assessment and Electrospinning of Different Collagen Formulations}

The choice of solvent and polymer concentration plays a critical role in the scaffold fabrication alongside electrospinning parameters such as flow rate, voltage, and collector distance. Solvents normally used for electrospinning applications have been found to significantly influence the native physico-chemical properties of collagen, while the process conditions mainly affect the final scaffold morphology and characteristics [13].

The electrospinning of natural polymers has reported different complications due to their high viscosity and low solubility, often requiring the addition of synthetic polymers or the use of organic toxic reagents, responsible for the evident denaturation of the protein native structure [11,12].

Based on these considerations, more environmentally benign and less harsh solvents were explored to obtain nanostructured collagen electrospun scaffolds. Accordingly, acidic solvent mixtures were evaluated to allow collagen solubilization at high concentrations as well as the native structure preservation.

As the starting point and based on previous studies in the literature [12], a solution of acetic acid (AA), ethyl acetate (EA) and distilled water $\left(\mathrm{dH}_{2} \mathrm{O}\right)$ with a ratio of 40:30:30 (AA/EA $/ \mathrm{dH}_{2} \mathrm{O}$ ) was prepared for collagen solubilization. The addition of ethyl acetate was tested to potentially increase the conductivity of the solution while supporting the 
formation of a stable electrostatic jet. In parallel, limiting the water component may be beneficial to improve the spinnability and avoid high surface tension $[12,13,18]$.

Collagen powders were dissolved at $120 \mathrm{mg} / \mathrm{mL}\left(12 \% \mathrm{BOV}-\mathrm{COL}\right.$ in $\left.\mathrm{AA} / \mathrm{EA} / \mathrm{dH}_{2} \mathrm{O}\right)$ and $200 \mathrm{mg} / \mathrm{mL}\left(20 \% \mathrm{BOV}-\mathrm{COL}\right.$ in $\left.\mathrm{AA} / \mathrm{EA} / \mathrm{dH}_{2} \mathrm{O}\right)$ in the previously prepared solvent (AA/EA/ $/ \mathrm{d}_{2} \mathrm{O}$ ) kept at $4{ }^{\circ} \mathrm{C}$, to evaluate the influence of increasing concentrations over the final material spinnability.

For the electrospinning tests, the jet stabilization was obtained, for each formulation, varying the applied voltage and the material flow between $18.5-20.0 \mathrm{kV}$ and 0.05 to $0.15 \mathrm{~mL} / \mathrm{h}$, respectively, using a plate collector and keeping constant conditions of temperature and humidity.

The resulting scaffolds were then collected and analyzed by means of scanning electron microscopy (SEM) in order to define their morphological features. (Figure 1).
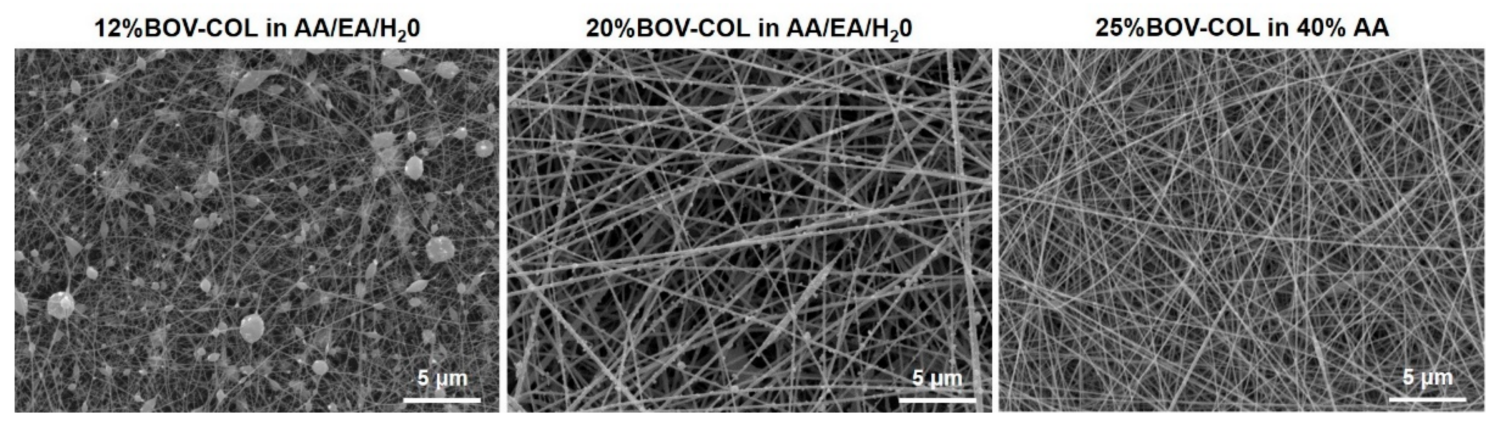

Figure 1. SEM images of scaffolds obtained from the electrospinning of $12 \% \mathrm{BOV}-\mathrm{COL}$ in $\mathrm{AA} / \mathrm{EA} / \mathrm{dH} \mathrm{H}_{2} \mathrm{O}, 20 \% \mathrm{BOV}-\mathrm{COL}$ in AA/EA/ $\mathrm{dH}_{2} \mathrm{O}$ and $25 \%$ BOV-COL in $40 \%$ AA.

The morphological assessment of scaffolds obtained by processing collagen solutions in $\mathrm{AA} / \mathrm{EA} / \mathrm{dH}_{2} \mathrm{O}$, revealed that the use of a lower concentration of collagen (12 $\mathrm{wt} \%$ ) resulted in meshes presenting a large number of beads of variable size embedded into the fibers scattered throughout the scaffold structure.

When the collagen concentration was increased up to $20 \mathrm{wt} \%$, the number of defects and beads decreased and the resulting scaffolds showed fibers from 100 to $400 \mathrm{~nm}$ (Figure S2B), characterized by a randomly oriented matrix.

As reported in the literature [38,39], the formation of beaded fibers during electrospinning of polymers is considered a quite common phenomenon, mainly due to the instability of the polymeric jet. Specifically, higher values of viscosity and net charge density of the jet as well as reduced surface tension have been observed to decrease the formation of beads, as confirmed by our results. Therefore, not only the concentration and physicochemical properties of the polymer but also the selected solvents play a key role in the final morphology of the electrospun fibers.

Besides the large presence of defects in the final matrix, the use of $\mathrm{AA} / \mathrm{EA} / \mathrm{dH}_{2} \mathrm{O}$ as collagen solvent led to a poor stability of the system, where a phase separation was observed after $1 \mathrm{~h}$ of material processing (Figure S1B). This effect was tentatively ascribed to the low solubility of bovine collagen powders in the prepared solvent mixture. Therefore, based on the potential negative effects over scaffold fabrication in the long term, an alternative solvent consisting in $40 \%$ acetic acid in water was assessed for further investigation.

Considering the high solubility of collagen in acetic acid and the demonstrated beneficial effects of increased collagen concentrations over the final fibrous structure $[11,14,15,35]$, a $25 \mathrm{wt} \%$ collagen concentration was chosen and dissolved in $40 \%$ acetic acid ( $40 \% \mathrm{AA})$. Upon complete dissolution, the $25 \% \mathrm{BOV}-\mathrm{COL}$ in $40 \%$ AA formulation was loaded in the syringe (Figure S1C) and electrospun at $20 \mathrm{kV}$ with a flow rate of $0.05 \mathrm{~mL} / \mathrm{h}$ and $15 \mathrm{~cm}$ of collector distance to obtain a stable material jet.

As reported in Figure 1, the resulting scaffolds presented homogeneous fibers characterized by a diameter of about $135.9 \pm 20.7 \mathrm{~nm}$ (Figure S2C), comparable to the morpholog- 
ical features observed when processing the $20 \% \mathrm{BOV}-\mathrm{COL}$ in $\mathrm{AA} / \mathrm{EA} / \mathrm{dH}_{2} \mathrm{O}$ formulation. Moreover, the collagen system proved to be stable during the process and no beads were observed in the resulting structure.

To further investigate the physico-chemical properties of the developed formulations and the potential influence of the two solvent systems, the variation of the viscosity values was registered by means of rheological analyses, as shown in Figure 2.
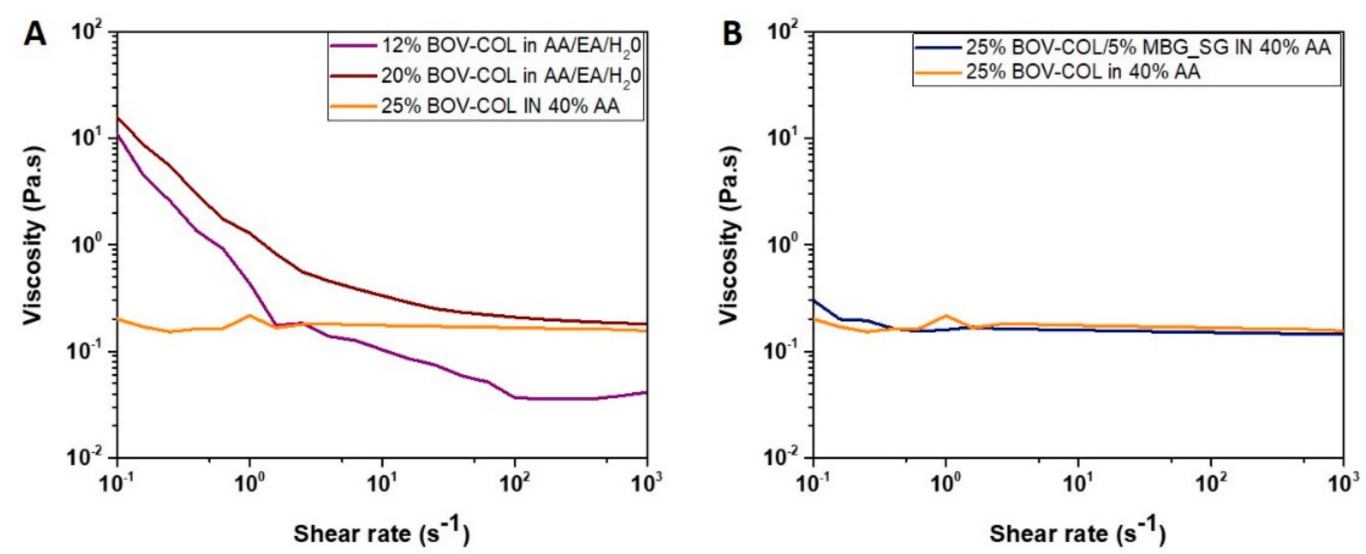

Figure 2. Comparison between flow ramps obtained from $12 \% \mathrm{BOV}-\mathrm{COL}$ in $\mathrm{AA} / \mathrm{EA} / \mathrm{dH}_{2} \mathrm{O}, 20 \% \mathrm{BOV}-\mathrm{COL}$ in $\mathrm{AA} / \mathrm{EA} / \mathrm{dH}_{2} \mathrm{O}$ and $25 \% \mathrm{BOV}-\mathrm{COL}$ in $40 \% \mathrm{AA}$ (A), and flow ramps of $25 \% \mathrm{BOV}-\mathrm{COL}$ in $40 \% \mathrm{AA}$ and $25 \% \mathrm{BOV}-\mathrm{COL} / 5 \% \mathrm{MBG}$ SG in $40 \%$ AA (B).

As shown in the graph presented in Figure 2A, 12 and 20\% BOV-COL in AA/EA/ $\mathrm{H}_{2} \mathrm{O}$ systems showed a shear thinning behavior and higher values of viscosity at almost zeroshear conditions. On the contrary, a higher concentration of collagen $(25 \mathrm{wt} \%)$ dissolved in $40 \%$ AA showed a Newtonian behavior, characterized by constant and lower values of viscosity in the wide range of applied shear rates.

These results confirmed the key role of acetic acid in promoting the dissolution of collagen molecules, associated with lower viscosity values, as previously reported [5]. Accordingly, the higher values of viscosity registered for collagen-dissolved AA/EA/ $\mathrm{H}_{2} \mathrm{O}$ suggested a lower solubilization of the protein.

\subsection{Assessment of the Preservation of the Supramolecular Structure of Collagen}

The high solubility of collagen molecules in acid solutions and organic solvents is due to the absence of covalent bonds between triple helices of collagen after extraction from native tissues [14]. Higher solubility of collagen is normally preferred to produce more stable and homogeneous solutions, thus allowing the electrospinning and the achievement of homogeneous sub-micrometric fibers, also supported by high polymeric concentrations.

However, as previously reported, the use of organic solvents and strong acids has been suggested to hinder the natural folding of collagen into triple helix, almost absent in the resulting electrospun scaffolds [11-14].

In this frame, the influence of AA/EA/ $\mathrm{H}_{2} \mathrm{O}$ and $40 \%$ AA solvents over the final supramolecular structure of collagen was investigated by means of circular dichroism spectroscopy, observing the potential decrease in the triple helical fraction.

The influence of the solvents alongside the electrospinning process was defined comparing native bovine collagen powders with collagen reconstituted after dissolution in both AA/EA/ $\mathrm{H}_{2} \mathrm{O}$ and $40 \% \mathrm{AA}$, and electrospun scaffolds obtained by the processing of $25 \%$ COL in $40 \%$ AA, as shown in Figure 3. 


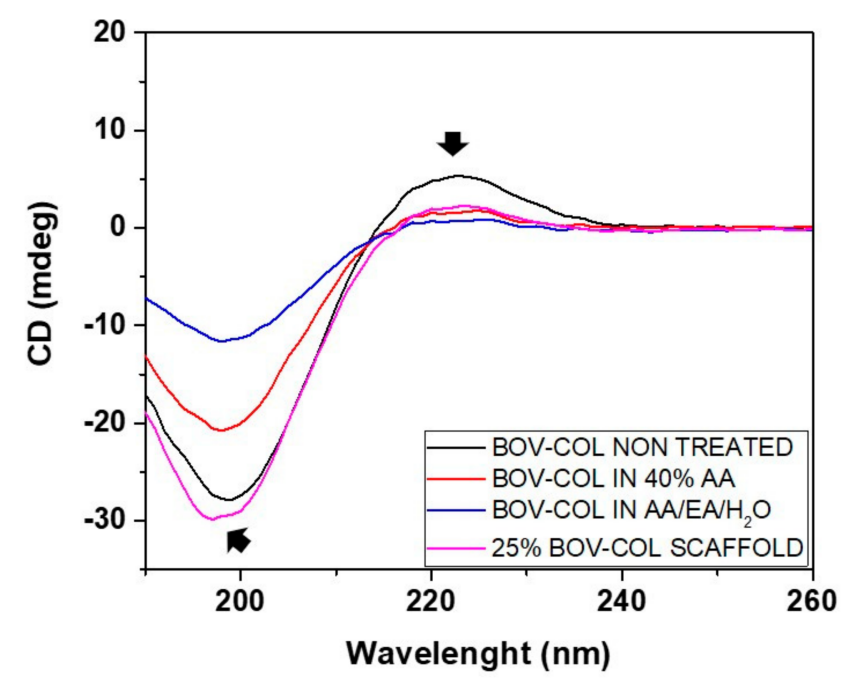

Figure 3. Circular dichroism analysis performed on native collagen (BOV-COL NON-TREATED), collagen reconstituted after dissolution in AA/EA/ $\mathrm{H}_{2} \mathrm{O}\left(\mathrm{BOV}-\mathrm{COL}\right.$ in $\left.\mathrm{AA} / \mathrm{EA} / \mathrm{H}_{2} \mathrm{O}\right)$, collagen reconstituted after dissolution in 40\% AA (BOV-COL in 40\%AA) and collagen scaffolds obtained by processing 25\% BOV-COL in 40\% AA (25\% BOV-COL SCAFFOLD).

The spectrum derived from original collagen powders (black curve) displayed a sinusoidal pattern with a deep negative peak at about $198 \mathrm{~nm}$, a cross-over around $215 \mathrm{~nm}$ and an evident positive peak at $220 \mathrm{~nm}$, indicating the presence of a triple helical configuration [20]. In detail, the negative peak is characteristic of randomly arranged $\alpha$-chains while the positive one corresponds to the triple helix structure, whose intensity decreases upon denaturation $[11,14]$.

In parallel, collagen reconstituted after dissolution in 40\% AA (BOV-COL in 40\%AA) and electrospun scaffolds obtained by processing 25\% BOV-COL in $40 \%$ AA (25\% BOV-COL SCAFFOLD) exhibited similar trends, comparable with that reported by native collagen, showing an evident negative peak at about $198 \mathrm{~nm}$ and a slightly weakened positive band at $222 \mathrm{~nm}$. Moreover, left shifts of the curves, normally related to a non-triple-helical conformation, were not detected, further confirming the previous comments.

On the contrary, collagen reconstituted after dissolution in $\mathrm{AA} / \mathrm{EA} / \mathrm{H}_{2} \mathrm{O}$ solvent (BOV-COL in AA/EA/ $\mathrm{H}_{2} \mathrm{O}$ ) lacked the positive peak, as normally occurs for gelatin and denatured collagen, due to the disruption of the triple helix conformation and the progressively dissociation into the randomly coiled $\alpha$-chains [11].

These results evidenced that the use of $40 \%$ AA and the further processing with electrospinning led to a greater preservation of the ultramolecular structure of collagen compared to the systems obtained from AA/EA/ $\mathrm{H}_{2} \mathrm{O}$ and other solvents, in accordance with previous studies reported in the literature $[11,14]$.

Based on the reported results and the demonstrated enhanced processability of the formulation, 25\% BOV-COL in 40\% AA was selected for further investigation regarding the combination with inorganic phases, in order to obtain biomimetic composite scaffolds for bone tissue engineering.

\subsection{Electrospinning of Composite Scaffolds}

The introduction of inorganic phases in the collagenous system is crucial to obtain biomimetic structures, mimicking the composite nature of bone tissue while reproducing its architecture at the micro- and nanoscale, exploiting electrospinning techniques. Accordingly, the use of MBGs in the form of spheroidal nanoparticles was explored, with the aim to enhance the overall bioactivity of the final constructs.

According to the literature, mesoporous bioactive glasses have largely proved their ability to stimulate bone regeneration, wherein the high surface area and regular nano- 
porosities also make these materials suitable as efficient delivery platforms for a variety of active molecules and therapeutic agents $[28,36,40]$.

Following the optimized sol-gel route reported by the authors in a previous work (Supplementary Material) [36], the resulting MBG_SG particles presented a spherical morphology, size ranging between 100 and $500 \mathrm{~nm}$, specific surface area between 400 and $500 \mathrm{~m}^{2} / \mathrm{g}$, and mesopores of $2-4 \mathrm{~nm}$. After preparation, MBG_SG particles were combined with the previously optimized collagen formulation; to this aim, the most straightforward strategy is to disperse them into the pre-formed collagen solution.

As preliminary assessment and based on previous studies reporting the processing of polymeric composite systems [13,15,19], MBG_SG were mixed with collagen to reach a final concentration of $5 \mathrm{wt} \%$, obtaining a homogeneous 25\% BOV-COL/MBG_SG in 40\% AA hybrid formulation.

According to the rheological analysis reported in Figure 2B, the collagen-based suspension showed a Newtonian behavior, registering low and constant values of viscosity, as observed for the $25 \%$ BOV-COL in $40 \%$ AA solution. Therefore, the introduction of MBG_SG did not alter the rheological properties of the system, suggesting a good dispersion of the nanoparticles as well as weak interactions between the inorganic and the organic phases [19].

Despite the similar rheological properties, the electrospinning of the $25 \% \mathrm{BOV}-\mathrm{COL} /$ MBG_SG in 40\% AA system showed better performances at different process parameters compared to the other collagen solutions. Specifically, the scaffolds were fabricated with $20 \mathrm{kV}$ voltage and flow rate of $0.1 \mathrm{~mL} / \mathrm{h}$, at $12 \mathrm{~cm}$ working distance. The resulting scaffolds were then collected and morphologically analyzed by means of SEM, as presented in Figure 4 .
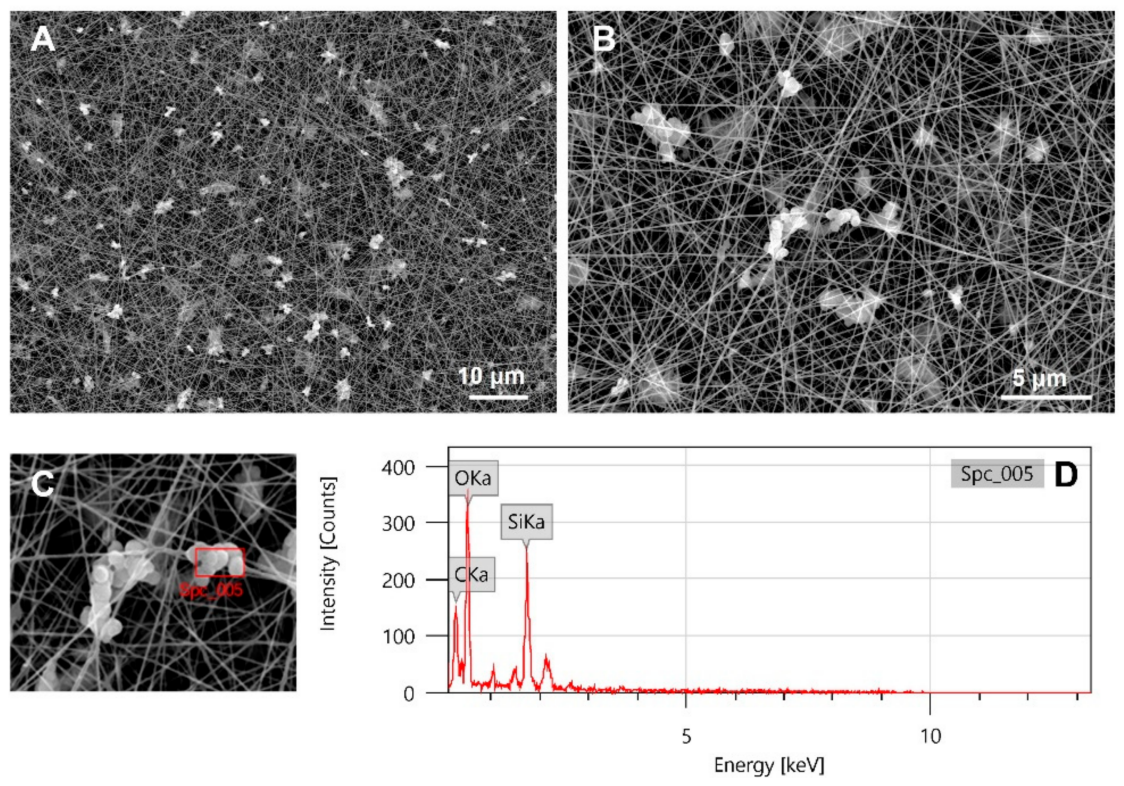

Figure 4. SEM images (A-C) and EDX analysis (D) of 25\% BOV-COL/MBG_SG scaffolds.

As visible from the SEM images, the resulting scaffolds were characterized by randomly oriented homogeneous fibers of about $120 \pm 10 \mathrm{~nm}$ (Figure S2D), which was comparable to the fibers formed during the electrospinning of collagen alone. The particles looked overall uniformly distributed and small aggregates of about $3 \mu \mathrm{m}$ were present throughout the scaffold, confirming that the dispersion process successfully limited their aggregation.

The collected scaffolds were further analyzed by means of Energy-dispersive X-ray spectroscopy (EDX) to confirm the composition and the distribution of nanoparticles 
throughout the matrix, discriminating from inorganic particles and potential collagen beads, as shown in Figure 4D.

At variance with the spectrum of $25 \%$ BOV-COL scaffolds reported in Figure S3, EDX spectrum of the $25 \%$ BOV-COL/MBG_SG scaffold revealed the presence of MBG_SG particles, evidencing the contribution of silica by $\mathrm{Si}$ and $\mathrm{O}$ peaks, whereas the peak of $\mathrm{C}$ clearly arose from the collagenous matrix.

The reported results were supported and confirmed by FTIR analysis, where the preservation of the collagen physico-chemical features was also investigated by comparing the spectrum of original collagen powders with the curves obtained from $25 \%$ BOV-COL and 25\% BOV-COL/MBG_SG scaffolds, as represented in Figure 5.
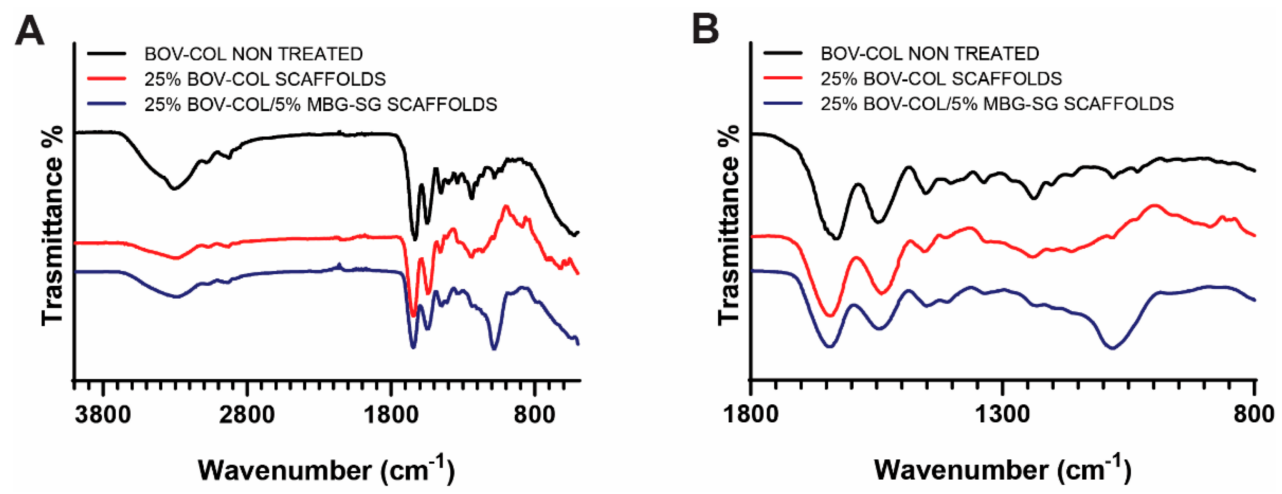

Figure 5. ATR-FTIR of 25\% BOV-COL and 25\% BOV-COL/MBG_SG scaffolds compared to native collagen (BOV-COL NON-TREATED): whole spectrum (A) and focus between 1800 and $800 \mathrm{~cm}^{-1}$ (B).

The spectrum of non-treated bovine collagen powders displayed the characteristic peaks at 3305 and $2922 \mathrm{~cm}^{-1}$ related to amide A and B bands, respectively, while peaks at 1628, 1548 and $1237 \mathrm{~cm}^{-1}$ were attributed to the amide I, amide II and amide II absorptions $[18,19]$.

As summarized in Table 1, the spectra of $25 \%$ BOV-COL and 25\% BOV-COL/MBG_SG scaffolds depicted similar patterns when compared with original collagen, without significant alterations in peak intensity of shifts. The slight shift of amide I in 25\% BOV-COL and $25 \%$ BOV-COL/MBG_SG scaffolds was ascribed to potential residuals of acetic acid, normally detected at about $1700 \mathrm{~cm}^{-1}$. However, the absence of an evident peak at $1700 \mathrm{~cm}^{-1}$ suggested an almost total removal of the solvent during the electrospinning process [12].

Table 1. FTIR characteristic peaks of collagen, 25\% BOV-COL and 25\% BOV-COL/MBG_SG scaffolds.

\begin{tabular}{|c|c|c|c|c|c|c|}
\hline Material & $\begin{array}{c}\text { Amide A } \\
\left(\mathrm{cm}^{-1}\right)\end{array}$ & $\begin{array}{c}\text { Amide B } \\
\left(\mathrm{cm}^{-1}\right)\end{array}$ & $\begin{array}{l}\text { Amide I } \\
\left(\mathrm{cm}^{-1}\right)\end{array}$ & $\begin{array}{l}\text { Amide II } \\
\left(\mathrm{cm}^{-1}\right)\end{array}$ & $\begin{array}{c}\text { Amide III } \\
\left(\mathrm{cm}^{-1}\right)\end{array}$ & $\begin{array}{l}\mathrm{Si}-\mathrm{O}-\mathrm{Si} \\
\left(\mathrm{cm}^{-1}\right)\end{array}$ \\
\hline BOV-COL (non-treated) & 3305 & 2922 & 1628 & 1548 & 1237 & - \\
\hline 25\%BOV-COL SCAFFOLDS & 3288 & 2930 & 1640 & 1540 & 1239 & - \\
\hline 25\%BOV-COL/5\%MBG_SG SCAFFOLDS & 3288 & 2932 & 1643 & 1544 & 1231 & 1082 \\
\hline
\end{tabular}

According to previous studies [11,12,14], significant shifts of amide I and II towards lower wavelength as well as the loss of amide III peak at about $1240 \mathrm{~cm}^{-1}$ indicate the presence of unfolded structures related to the partial or total denaturation of the protein. As reported by previous studies [41], the amide I band resonates at different wavenumbers depending on the secondary structure of the protein. Specifically, $\beta$-turns resonate from 1660 to $1700 \mathrm{~cm}^{-1}, \alpha$-helices from 1645 to $1659 \mathrm{~cm}^{-1}$, irregular structures from 1640 to $1644 \mathrm{~cm}^{-1}$ and $\beta$-sheets from 1620 to $1640 \mathrm{~cm}^{-1}$, where shifts to lower frequencies are indicative of higher hydrogen bonding potential. Therefore, the detection of amide III peak in both 25\% BOV-COL and 25\% BOV-COL/MBG_SG spectra, as well as the absence of significant shifts for amide I and II, suggested the good preservation of the integrity of 
collagen triple helices structures, confirming the results obtained by circular dichroism analysis.

To further confirm this result, the ratio between peaks at $1240 \mathrm{~cm}^{-1}$ (amide III) and $1450 \mathrm{~cm}^{-1}$ was calculated to be about 0.9 for both native and electrospun collagen, wherein values around 1 are indicative of a triple helical structure and values around 0.5 suggests the protein denaturation [41]. As additional observation, 25\% BOV-COL/MBG_SG presented a less evident band for amide III at $1231 \mathrm{~cm}^{-1}$ due to the contribution of Si-O-Si band centered at about $1082 \mathrm{~cm}^{-1}$ of MBG_SG nanoparticles. The similar values registered for the different spectra also indicated that the addition of MBG_SG and the applied conditions did not destabilize the secondary structure of collagen.

The characterization performed on the developed electrospun composite scaffolds evidenced the successful achievement of homogeneous matrices reproducing the architectural feature of the native extracellular matrix of bone at the nanoscale. Moreover, the developed strategies proved to have less impact on the physico-chemical properties of type I collagen, preserving the supramolecular structure, in contrast with other studies reported in the literature $[11,14]$.

Based on these results and the well-known high bioactive character of constructs consisting of type I collagen and MBGs [24], future studies will be focused on the optimization of the composite scaffolds in terms of mechanical and biological features, with the aim to boost their potential in bone tissue regeneration.

\section{Conclusions}

The outcomes achieved in this study confirmed the processability of collagen-based formulations for the design of biomimetic nanostructures scaffolds by means of electrospinning technologies and highlight that a strict control of polymeric concentration, solvents and process conditions is essential to obtain homogeneous systems and stable material jets.

The proper selection of solvents and electrospinning conditions proved to highly affect the preservation of the physico-chemical properties of collagen as well as the final morphological features of the scaffolds. In this frame, $40 \%$ acetic acid solution was used to dissolve high concentrations of bovine collagen powders ( $25 \mathrm{wt} \%)$ to obtain a final system able to be processed by means of electrospinning and forming homogeneous fibrous scaffolds with fibers measuring about $100 \mathrm{~nm}$ in diameter. On the contrary, the use of acetic acid (AA), ethyl acetate (EA), and distilled water $\left(\mathrm{dH}_{2} \mathrm{O}\right)$ with a ratio of 40:30:30 and lower concentrations of collagen (12 and $20 \mathrm{wt} \%$ ) led to the formation of less homogeneous fibrous scaffolds presenting a great number of defects.

The electrospinning of collagen thus evidenced the promising advantage of replicating the nano-architecture of the bone tissue, characterized by collagen fibrils ranging between tens of nanometers up to few microns. Alongside the morphological aspects, the introduction of bioactive reinforcing inorganic phases was exploited to boost the potential regenerative effect of the final scaffolds. Based on the well-known bioactive character of mesoporous bioactive glasses and the limited data in the literature presenting their combination with collagen for electrospinning applications, nano-sized mesoporous bioactive glasses $(5 \mathrm{wt} \%)$ were successfully incorporated into the collagen system previously optimized and composed of $25 \mathrm{wt} \%$ collagen dissolved in $40 \%$ acetic acid.

The resulting scaffolds presented a uniform nano-fibrous pattern and the homogeneous distribution of inorganic particles throughout the collagen matrix, while the further characterization of the constructs confirmed the preservation of the physico-chemical properties of collagen.

The promising results presented in this study thus pave the way for the design of new composite bioactive scaffolds based on type I collagen and MBGs, able to mimic the features of the native bone ECM and without altering the physico-chemical properties of collagen, crucial to obtain an effective biological response. Accordingly, based on the well-known biocompatibility and bioactivity of both collagen and bioactive glass particles, future studies will be focused on the investigation of scaffold-cell interactions, with the 
aim to better understand the potential influence of the developed systems over the bone tissue regeneration process.

Supplementary Materials: The following are available online at https:/ /www.mdpi.com/article/ 10.3390 /ma14164360/s1, Figure S1: Image showing the 20\%BOV-COL in AA/EA/H2O solution immediately after preparation (A) and the phase separation after 1 hour of processing (B), compared to $25 \%$ BOV-COL in $40 \%$ AA solution immediately after preparation (C) and after 1 hour of processing (D)., Figure S2: Fiber diameter distribution of 12\%BOV-COL in AA/EA/H2O (A), 20\%BOV-COL in AA/EA/H2O (B), 25\%BOV-COL in 40\% AA (C) and 25\% BOV-COL/MBG_SG (D). Histograms have been obtained by the analysis of SEM images, on 100 fibers for each material. Figure S3: EDS analysis performed on $25 \%$ BOV-COL scaffolds.

Author Contributions: For this research paper, C.V.-B. and L.M. formulated the research ideas; G.M. and C.T. developed the systems and interpreted the results under the supervision of L.M.; C.V.-B., S.C.-E., S.F., G.M. and C.T. wrote the manuscript and all other authors revised the manuscript and contributed to the discussion of the results. Conceptualization, L.M., C.V.-B., S.C.-E. and S.F.; methodology, G.M., C.T. and S.C.-E.; software, G.M. and C.T.; validation, G.M., C.T., L.M., C.V.-B., S.C.-E. and S.F.; formal analysis, G.M. and C.T.; investigation, G.M., C.T. and S.C.-E.; resources, L.M. and C.V.-B.; data curation, G.M., C.T. and S.C.-E.; writing-original draft preparation, G.M. and C.T.; writing-review and editing, L.M., C.V.-B., S.C.-E. and S.F.; visualization, S.C.-E. and S.F.; supervision, L.M., C.V.-B., S.C.-E. and S.F.; project administration, C.V.-B.; funding acquisition, L.M. and C.V.-B. All authors have read and agreed to the published version of the manuscript.

Funding: This project has received funding from the European Union's Horizon 2020 research and innovation programme under grant agreement No 814410 (GIOTTO).

Institutional Review Board Statement: Not applicable.

Informed Consent Statement: Not applicable.

Data Availability Statement: The data presented in this study are openly available in ZENODO at https:/ / doi.org/10.5281/zenodo.5156181 (accessed on 4 August 2021).

Conflicts of Interest: The authors declare no conflict of interest.

\section{References}

1. Johnson, C.D.L.; Ganguly, D.; Zuidema, J.M.; Cardinal, T.J.; Ziemba, A.M.; Kearns, K.R.; McCarthy, S.M.; Thompson, D.M.; Ramanath, G.; Borca-Tasciuc, D.-A.; et al. Injectable, Magnetically Orienting Electrospun Fiber Conduits for Neuron Guidance. ACS Appl. Mater. Interfaces 2018, 11, 356-372. [CrossRef]

2. Zadpoor, A.A.; Malda, J. Additive Manufacturing of Biomaterials, Tissues, and Organs. Ann. Biomed. Eng. 2017, 45, 1-11. [CrossRef]

3. Jakob, F.; Ebert, R.; Ignatius, A.; Matsushita, T.; Watanabe, Y.; Groll, J.; Walles, H. Bone tissue engineering in osteoporosis. Maturitas 2013, 75, 118-124. [CrossRef]

4. Glowacki, J.; Mizuno, S. Collagen scaffolds for tissue engineering. Biopolymers 2008, 89, 338-344. [CrossRef]

5. Henkel, J.; Woodruff, M.; Epari, D.; Steck, R.; Glatt, V.; Dickinson, I.C.; Choong, P.; Schuetz, M.A.; Hutmacher, D.W. Bone Regeneration Based on Tissue Engineering Conceptions-A 21st Century Perspective. Bone Res. 2013, 1, 216-248. [CrossRef] [PubMed]

6. Ghassemi, T.; Shahroodi, A.; Ebrahimzadeh, M.H.; Mousavian, A.; Movaffagh, J.; Moradi, A. Current Concepts in Scaffolding for Bone Tissue Engineering. Arch. Bone Jt. Surg. 2018, 6, 90-99. [PubMed]

7. Frantz, C.; Stewart, K.M.; Weaver, V.M. The extracellular matrix at a glance. J. Cell Sci. 2010, 123, 4195-4200. [CrossRef]

8. Alford, A.I.; Kozloff, K.M.; Hankenson, K.D. Extracellular matrix networks in bone remodeling. Int. J. Biochem. Cell Biol. 2015, 65, 20-31. [CrossRef] [PubMed]

9. Zhang, D.; Wu, X.; Chen, J.; Lin, K. The development of collagen based composite scaffolds for bone regeneration. Bioact. Mater. 2018, 3, 129-138. [CrossRef] [PubMed]

10. Ferreira-Duarte, A.; Gentile, P.; Chiono, V.; Ciardelli, G. Collagen for bone tissue regeneration. Acta Biomater. 2012, 8, 3191-3200. [CrossRef] [PubMed]

11. Zeugolis, D.; Khew, S.T.; Yew, E.S.; Ekaputra, A.K.; Tong, Y.W.; Yung, L.-Y.L.; Hutmacher, D.W.; Sheppard, C.; Raghunath, M. Electro-spinning of pure collagen nano-fibres-Just an expensive way to make gelatin? Biomaterials 2008, 29, $2293-2305$. [CrossRef]

12. Ribeiro, N.; Sousa, S.R.; van Blitterswijk, C.; Moroni, L.; Monteiro, F. A biocomposite of collagen nanofibers and nanohydroxyapatite for bone regeneration. Biofabrication 2014, 6, 035015. [CrossRef] 
13. Sell, S.; McClure, M.J.; Garg, K.; Wolfe, P.S.; Bowlin, G.L. Electrospinning of collagen/biopolymers for regenerative medicine and cardiovascular tissue engineering. Adv. Drug Deliv. Rev. 2009, 61, 1007-1019. [CrossRef]

14. Fiorani, A.; Gualandi, C.; Panseri, S.; Montesi, M.; Marcacci, M.; Focarete, M.L.; Bigi, A. Comparative performance of collagen nanofibers electrospun from different solvents and stabilized by different crosslinkers. J. Mater. Sci. Mater. Med. 2014, 25, 2313-2321. [CrossRef]

15. Schiffman, J.; Schauer, C.L. A Review: Electrospinning of Biopolymer Nanofibers and their Applications. Polym. Rev. 2008, 48, 317-352. [CrossRef]

16. Cen, L.; Liu, W.; Cui, L.; Zhang, W.; Cao, Y. Collagen Tissue Engineering: Development of Novel Biomaterials and Applications. Pediatr. Res. 2008, 63, 492-496. [CrossRef] [PubMed]

17. Rho, K.S.; Jeong, L.; Lee, G.; Seo, B.-M.; Park, Y.J.; Hong, S.-D.; Roh, S.; Cho, J.J.; Park, W.H.; Min, B.-M. Electrospinning of collagen nanofibers: Effects on the behavior of normal human keratinocytes and early-stage wound healing. Biomaterials 2006, 27, 1452-1461. [CrossRef] [PubMed]

18. Dong, B.; Arnoult, O.; Smith, M.E.; Wnek, G.E. Electrospinning of Collagen Nanofiber Scaffolds from Benign Solvents. Macromol. Rapid Commun. 2009, 30, 539-542. [CrossRef]

19. Yao, H.; Wang, J.; Wang, D. Greener synthesis of electrospun collagen / hydroxyapatite composite fibers with an excellent microstructure for bone tissue engineering. Int. J. Nanomed. 2015, 10, 3203-3215.

20. Jiang, Q.; Reddy, N.; Zhang, S.; Roscioli, N.; Yang, Y. Water-stable electrospun collagen fibers from a non-toxic solvent and crosslinking system. J. Biomed. Mater. Res. Part A 2012, 101, 1237-1247. [CrossRef]

21. Villarreal-Gómez, L.J.; Cornejo-Bravo, J.M.; Vera-Graziano, R.; Grande, D.; Jesús, V.-G.L.; Manuel, C.-B.J.; Ricardo, V.-G.; Daniel, G. Electrospinning as a Powerful Technique for Biomedical Applications: A Critically Selected Survey. J. Biomater. Sci. Polym. Ed. 2015, 27, 1-32. [CrossRef]

22. Teng, S.-H.; Lee, E.-J.; Wang, P.; Kim, H.-E. Collagen/hydroxyapatite composite nanofibers by electrospinning. Mater. Lett. 2008, 62, 3055-3058. [CrossRef]

23. Izquierdo-Barba, I.; Vallet-Regí, M. Mesoporous bioactive glasses: Relevance of their porous structure compared to that of classical bioglasses. Biomed. Glasses 2015, 1, doi. [CrossRef]

24. Boccaccini, A.R.; Erol, M.; Stark, W.J.; Mohn, D.; Hong, Z.; Mano, J.F. Polymer/bioactive glass nanocomposites for biomedical applications: a review. Compos. Sci. Technol. 2010, 70, 1764-1776. [CrossRef]

25. Fiorilli, S.; Pontremoli, C.; Montalbano, G.; Vitale-brovarone, C. Hybrid formulations based on mesoporous bioactive glasses/polymeric phases for the desig of bone scaffolds and delivery platforms. In Bioactive Glasses-Properties, Composition and Recent Applications; Arcos, D., Vallet-Regi, M., Eds.; NOVA: Nagoya, Japan, 2020; p. 412. ISBN 9781631172557.

26. Hsu, F.-Y.; Lu, M.-R.; Weng, R.-C.; Lin, H.-M. Hierarchically biomimetic scaffold of a collagen-mesoporous bioactive glass nanofiber composite for bone tissue engineering. Biomed. Mater. 2015, 10, 25007. [CrossRef]

27. Pontremoli, C.; Boffito, M.; Fiorilli, S.; Laurano, R.; Torchio, A.; Bari, A.; Tonda-Turo, C.; Ciardelli, G.; Vitale-Brovarone, C. Hybrid injectable platforms for the in situ delivery of therapeutic ions from mesoporous glasses. Chem. Eng. J. 2018, 340, 103-113. [CrossRef]

28. Fiorilli, S.; Molino, G.; Pontremoli, C.; Iviglia, G.; Torre, E.; Cassinelli, C.; Morra, M.; Vitale-Brovarone, C. The Incorporation of Strontium to Improve Bone-Regeneration Ability of Mesoporous Bioactive Glasses. Materials 2018, 11, 678. [CrossRef]

29. López-Noriega, A.; Arcos, D.; Izquierdo-Barba, I.; Sakamoto, Y.; Terasaki, O.; Vallet-Regí, M. Ordered Mesoporous Bioactive Glasses for Bone Tissue Regeneration. Chem. Mater. 2006, 18, 3137-3144. [CrossRef]

30. $\mathrm{Wu}, \mathrm{C}$; Chang, J. Mesoporous bioactive glasses: Structure characteristics, drug/growth factor delivery and bone regeneration application. Interface Focus 2012, 2, 292-306. [CrossRef] [PubMed]

31. Sarker, B.; Hum, J.; Nazhat, S.N.; Boccaccini, A.R. Combining Collagen and Bioactive Glasses for Bone Tissue Engineering: A Review. Adv. Heal. Mater. 2015, 4, 176-194. [CrossRef] [PubMed]

32. El-Fiqi, A.; Lee, J.H.; Lee, E.-J.; Kim, H.-W. Collagen hydrogels incorporated with surface-aminated mesoporous nanobioactive glass: Improvement of physicochemical stability and mechanical properties is effective for hard tissue engineering. Acta Biomater. 2013, 9, 9508-9521. [CrossRef]

33. Montalbano, G.; Fiorilli, S.; Caneschi, A.; Vitale-Brovarone, C. Type I Collagen and Strontium-Containing Mesoporous Glass Particles as Hybrid Material for 3D Printing of Bone-Like Materials. Materials 2018, 11, 700. [CrossRef] [PubMed]

34. Montalbano, G.; Borciani, G.; Vitale-Brovarone, C.; Cerqueni, G.; Licini, C.; Banche-Niclot, F.; Janner, D.; Sola, S.; Fiorilli, S.; Mattioli-Belmonte, M.; et al. Collagen Hybrid Formulations for the 3D Printing of Nanostructured Bone Scaffolds: An Optimized Genipin-Crosslinking Strategy. Nanomaterials 2020, 10, 1681. [CrossRef] [PubMed]

35. Liu, T.; Teng, W.K.; Chan, B.P.; Chew, S.Y. Photochemical crosslinked electrospun collagen nanofibers: Synthesis, characterization and neural stem cell interactions. J. Biomed. Mater. Res. Part A 2010, 95, 276-282. [CrossRef] [PubMed]

36. Fiorilli, S.; Pagani, M.; Boggio, E.; Gigliotti, C.; Dianzani, C.; Gauthier, R.; Pontremoli, C.; Montalbano, G.; Dianzani, U.; VitaleBrovarone, C. Sr-Containing Mesoporous Bioactive Glasses Bio-Functionalized with Recombinant ICOS-Fc: An In Vitro Study. Nanomaterials 2021, 11, 321. [CrossRef] [PubMed]

37. Melo, P.; Naseem, R.; Corvaglia, I.; Montalbano, G.; Pontremoli, C.; Azevedo, A.; Quadros, P.; Gentile, P.; Ferreira, A.M.; Dalgarno, K.; et al. Processing of $\mathrm{Sr}^{2+}$ Containing Poly L-Lactic Acid-Based Hybrid Composites for Additive Manufacturing of Bone Scaffolds. Front. Mater. 2020, 7, 1-12. [CrossRef] 
38. Pelipenko, J.; Kristl, J.; Janković, B.; Baumgartner, S.; Kocbek, P. The impact of relative humidity during electrospinning on the morphology and mechanical properties of nanofibers. Int. J. Pharm. 2013, 456, 125-134. [CrossRef] [PubMed]

39. Fong, H.; Chun, I.; Reneker, D.H. Beaded nanofibers formed during electrospinning. Polymer 1999, 40, 4585-4592. [CrossRef]

40. Baino, F.; Fiorilli, S.; Vitale-Brovarone, C. Bioactive glass-based materials with hierarchical porosity for medical applications: Review of recent advances. Acta Biomater. 2016, 42, 18-32. [CrossRef]

41. Ahmad, M.; Benjakul, S.; Nalinanon, S. Compositional and physicochemical characteristics of acid solubilized collagen extracted from the skin of unicorn leatherjacket (Aluterus monoceros). Food Hydrocoll. 2010, 24, 588-594. [CrossRef] 